\title{
Ultraviolet Radiation/persulphate/hydrogen Peroxide Treatment System for Acid Blue 80 Dye Degradation of Batch Flow Chemical Reactor: Effects of Operational Parameters, Mineralisation, Energy Consumption, and Kinetic Studies
}

\section{Tariq Al-Musawi}

Al-Mustaqbal University College

\section{Murat Yilmaz}

Osmaniye Korkut Ata Üniversitesi: Osmaniye Korkut Ata Universitesi

\section{Amir Mahvi}

Tehran University of Medical Sciences

\section{Samaneh Mohebi}

Zahedan University of Medical Sciences

davoud balarak ( $\square$ dbalarak2@gmail.com )

Zahedan University of Medical Sciences https://orcid.org/0000-0003-3679-9726

\section{Research Article}

Keywords: UV/PS/H2O2, Acid blue 80 dye, Mineralisation, Radicals, Toxicity

Posted Date: November 29th, 2021

DOI: https://doi.org/10.21203/rs.3.rs-1071698/v1

License: (a) (1) This work is licensed under a Creative Commons Attribution 4.0 International License. Read Full License 
1 Ultraviolet radiation/persulphate/hydrogen peroxide treatment system for acid blue 80

7 Hillah, Iraq.

8 (n) , Hillah, Iraq.

Tariq J. Al-Musawi ${ }^{1}$, Murat Yilmaz ${ }^{2}$, Amir Hossein Mahvi ${ }^{3}$, Samaneh Mohebi ${ }^{4}$, Davoud Balarak $^{5 *}$

${ }^{1}$ Al-Mustaqbal University College, Chemical Engineering and Petroleum Industries, Al-

${ }^{2}$ Osmaniye Korkut Ata University, Faculty of Engineering, Department of Chemical Engineering, 80000, Osmaniye, Turkey

${ }^{3}$ Center for Solid Waste Research, Institute for Environmental Research, Tehran University 1 of Medical Sciences, Tehran, Iran.

${ }^{4}$ Student Research Committee, Zahedan University of Medical Sciences, Zahedan, Iran.

$3{ }^{5}$ Department of Environmental Health, Health Promotion Research Center, Zahedan University of Medical Sciences, Zahedan, Iran. 


\section{Abstract}

This study offers a comprehensive investigation into the efficiency of degradation of acid blue 80 (AB80) dye using a system using ultraviolet (UV) radiation combined with hydrogen peroxide $\left(\mathrm{H}_{2} \mathrm{O}_{2}\right)$ and persulphate (PS) oxidants (UV/PS/ $\left.\mathrm{H}_{2} \mathrm{O}_{2}\right)$. The degradation reactions were performed under different values of PS and $\mathrm{H}_{2} \mathrm{O}_{2}$ concentrations, initial $\mathrm{AB} 80$ dye concentration, $\mathrm{pH}$, UV intensity, and contact time. The results revealed that the $\mathrm{UV} / \mathrm{H}_{2} \mathrm{O}_{2}$ provided the best performance at $\mathrm{pH}$ of 5 , while the best performance for the UV/PS and UV/PS/ $\mathrm{H}_{2} \mathrm{O}_{2}$ systems was obtained at $\mathrm{pH}$ of 7 . Besides, $15 \mathrm{mmol}$ was found to be the optimum concentration for both oxidants. The efficiency of the combined process of the UV/PS/ $\mathrm{H}_{2} \mathrm{O}_{2}$ was higher than that of the other two processes i.e., UV/PS and $\mathrm{UV} / \mathrm{H}_{2} \mathrm{O}_{2}$, which was $98.2 \%$ for a dye concentration of $25 \mathrm{mg} / \mathrm{L}$. Further, the $\mathrm{BOD}_{5} / \mathrm{COD}$ ratios at the beginning and end of the UV/PS/ $\mathrm{H}_{2} \mathrm{O}_{2}$ process were 0.19 and 0.52 , respectively, indicative of the conversion of the non-biodegradable dye molecules to biodegradable compounds. The toxicity test was performed using the bioassay method with Daphnia magna, and $90 \%$ reduction in toxicity was observed in the effluent. The lethal concentration 50 (LC50) indicator was found to be 4.7 $\mathrm{mg} / \mathrm{L}$ for the dye solution. The results also revealed that the degradation data followed the pseudo-first-order kinetics, and the reaction rate constant was higher for the UV/PS/ $\mathrm{H}_{2} \mathrm{O}_{2}$ system than for the other systems. The rate of mineralisation by this process was 0.92 . Scavenging studies also showed that both the sulphate $\left(\mathrm{SO}_{4}^{\circ}\right)$ and hydroxyl $\left(\mathrm{OH}^{\circ}\right)$ radicals play an important role in the degradation process. Energy consumption in the $\mathrm{UV} / \mathrm{H}_{2} \mathrm{O}_{2}$, UV/PS, and UV/PS/ $\mathrm{H}_{2} \mathrm{O}_{2}$ processes was $61,47.8$, and $20.8 \mathrm{kWh} / \mathrm{m}^{3}$, respectively. On conclusion, the $\mathrm{UV} / \mathrm{PS} / \mathrm{H}_{2} \mathrm{O}_{2}$ is an effective and applicable process for the treatment of dye in wastewater, particularly when the medium is neutral.

Keywords: UV/PS/ $\mathrm{H}_{2} \mathrm{O}_{2}$; Acid blue 80 dye; Mineralisation; Radicals; Toxicity 


\section{Introduction}

Industrial effluents are usually one of the major environment-polluting wastes (Adeniyi et al., 2019). Coloured wastewater is released from several industries namely, the textile and dyeing industries, pharmaceutical and food industries, and paper and leather industries, as well as in the production of cosmetics (Adeogun et al., 2017). The textile industry is one of the principal and basic industries in any country (Ali et al., 2018). In spite of the fundamental importance of the textile industry, the environmental impact it exerts is of great concern (Balarak et al., 2018). Normally, colour is the main characteristic of such effluents from these types of industries, caused by the use of coloured materials during the processes (Balarak et al., 2016). The generation of large quantities of wastewater having different qualities has been addressed as one of the main environmental issues related to this industry (Al-Musawi et al., 2021). In the dyeing processes, about $15 \%$ of the total dye produced, mixes with the wastewater thus forming coloured wastewater (Bulut et al., 2007). Most often the dyes used in these industries are synthetic ones. Synthetic dyes are normally distinguishable as acidic, reactive, direct, and base dyes, besides other groups (Dotto et al., 2011). The pigments are chiefly composed of one or more benzene rings which, due to their toxicity and slow decomposition, can irreparably damage the environment, if they are released into nature without treatment (Goshadrou et al., 2011; Gupta et al., 2013). Therefore, such effluents must be treated with appropriate methods prior to being discharged into the environment. Treating textile wastewater has been evaluated with many methods. Biological processes are the commonest methods employed in the treatment of wastewater containing dye solutions because they are inexpensive and environmentally friendly (Sillanpää et al., 2021). Nevertheless, the limitations in the degradation of biodegradable compounds have been identified for these processes since the textile-industry generated wastewater contains some toxic compounds, which curb or limit the growth and activity of the microorganisms (Igwegbe et al., 2016; Iram et al., 2010). A few 
other processes, e.g., coagulation and adsorption, which are physico-chemical processes, can effectually remove the pollutants from the wastewater (Jauris et al., 2016). However, they can participate only in the transfer of organic matter from the liquid medium to the solid medium, which results in the production of a thick sludge that requires further treatment (Machado et al., 2016). Another effective technology used in the separation of pollutants from wastewater is membrane technology. Nevertheless, because of the possibility for fouling the membrane modules, the operating costs are observed to escalate (Menkiti et al., 2018; Azarpira et al., 2016). Electrochemical processes for petrochemical wastewater have also been studied; however, its large-scale application is limited due to high electrical energy consumption (Balarak et al., 2021).

Employing technologies such as advanced oxidation in water and wastewater treatment have many advantages. Fast vaporisation, less sludge production, a wide range of different types of pollutants in the aquatic environments, mineralisation of most organic compounds in these environments, besides others are some of the advantages offered by these technologies (Balarak et al., 2019). In the last decade UV-assisted photolysis has been used effectively in the elimination of organic compounds, exhibiting various kinetics and mechanisms, with byproducts released as the degradation products of these compounds (Al-Musawi et al., 2021). The basis of the Advanced Oxidation Processes (AOPs) was found to be the production of free radicals; the radicals thus produced are powerful, possessing high reactivity for the effective degradation of the organic pollutants. These radicals can be produced in a variety of ways, the commonest being the use of a chemical oxidising agent, such as $\mathrm{H}_{2} \mathrm{O}_{2}$ (Baeza et al., 2011).

Recently, PS has been identified as a good alternative oxidant for the production of free radicals possessing the capacity to degrade various types of pollutants. In order to produce free radicals, these oxidants must be activated, either through the use of ultraviolet radiation (UV), transition 
metals, and ultrasound; these can lead to the generation of $\mathrm{OH}^{\circ}$ or $\mathrm{SO}_{4}^{\circ}$ radicals, in the presence of $\mathrm{H}_{2} \mathrm{O}_{2}$ and $\mathrm{S}_{2} \mathrm{O}_{8}^{-2}$, respectively (Canonica et al., 2011; Keen et al., 2008).

$\mathrm{S}_{2} \mathrm{O}_{8}^{-2}+\mathrm{hv} \rightarrow 2 \mathrm{SO}_{4}^{-}$

$\mathrm{H}_{2} \mathrm{O}_{2}+\mathrm{hv} \rightarrow 2 \mathrm{OH}^{\circ}$

The $\mathrm{OH}^{\circ}$ and $\mathrm{SO}_{4}^{\circ}$ radicals are strong oxidising agents with $\mathrm{E} 0=2.7 \mathrm{~V}$ and $\mathrm{E} 0=2.6-3.1 \mathrm{~V}$, respectively. The $\mathrm{OH}^{\circ}$ radical is a non-selective oxidant with a $20 \mathrm{~nm}$ lifetime (lifetime $=20$ ns), while the $\mathrm{SO}_{4}^{\circ}$ radical is a selective oxidant, having a longer lifespan (40 $\left.\mu \mathrm{s}\right)$. Therefore, the $\mathrm{SO}_{4}^{-}$radical has greater opportunity of reacting with the organic compounds (Ahmed et al., 2012; Yang et al., 2016). The main purpose of this study is to compare the UV/PS and $\mathrm{UV} / \mathrm{PC}$ and the combined process of $\mathrm{UV} / \mathrm{PS} / \mathrm{H}_{2} \mathrm{O}_{2}$ in the removal of the $\mathrm{AB} 80$ dye from aqueous solutions. In this study, the quantity of mineralisation will be determined using the TOC and the degree of biodegradability will be calculated using the $\mathrm{BOD}_{5} / \mathrm{COD}$ ratio. Also, the effect of various parameters such as contact time, oxidant concentration, $\mathrm{pH}$ and initial concentration of the AB80 dye were investigated. Further, to gain an economic perspective, the energy consumption was calculated for each system.

\section{Materials and methods}

\subsection{Chemicals}

The AB80 dye with the chemical formula of $\mathrm{C}_{32} \mathrm{H}_{28} \mathrm{~N}_{2} \mathrm{Na}_{2} \mathrm{O}_{8} \mathrm{~S}_{2}$, molecular weight of 678.6 g/mol, and CAS number of 4474-24-2 was purchased from the Sigma Aldrich Company. The stock solution of $1000 \mathrm{mg} / \mathrm{L}$ of dye was obtained by dissolving one gram of dye in $1 \mathrm{~L}$ of distilled water; the solutions necessary for this experiment were obtained by diluting the stock solution. The $\mathrm{H}_{2} \mathrm{O}_{2}(30 \%$ w/w), and sodium persulphate (99\%) prepared using Merck pellets GR (99-100\%) and the $\mathrm{HCl}$ solution prepared from $37 \%$ stock solution were all purchased from 
Merck. All the aqueous solutions were prepared utilising double distilled water with less than $0.08 \mu \mathrm{S} / \mathrm{cm}$ conductivity.

\subsection{Experimental setup}

The batch mode was considered for performing the photo-oxidation process at room temperature, with the use of a cylindrical quartz reactor $(6 \mathrm{~cm}$ in diameter and $16 \mathrm{~cm}$ in height $)$ containing $500 \mathrm{ml}$ of coloured wastewater. The distance between the lamps and reactor was 3 cm. In fact, 1 to $4 \mathrm{UV}-\mathrm{C}$ lamps in number ( $8 \mathrm{~W}$, Philips) were used, with the maximum emission at $254 \mathrm{~nm}$. Safe operation conditions were ensured by placing the reactor and lamps in a wooden box, to prevent the penetration of excess UV light. Due to the heat generated by the lamps, the reaction chamber was placed in a bath equipped with a water inlet and an outlet pipe, to adjust the temperature. For the UV lamps to achieve a steady state a heating process was provided for 10 minutes, prior to photo-oxidation. The intensity of the lamps, in the centre of the reactor, was assessed as $7.25 \mathrm{~mW} / \mathrm{cm}^{2}$. After pouring the samples into the reactor, the pH was adjusted using $0.1 \mathrm{~N} \mathrm{HCl}$ or $\mathrm{NaOH}$. Next, a specific quantity of the oxidant $\left(\mathrm{H}_{2} \mathrm{O}_{2}\right.$ and PS) was added to the sample, while the solution was stirred with a magnetic stirrer. The initial $\mathrm{pH}$ values were in the 3 to 11 range, while the oxidant doses ranged from 2 to $20 \mathrm{mmol}$ for $\mathrm{H}_{2} \mathrm{O}_{2}$ and PS, respectively. The quantities of the $\mathrm{pH}$ adjusting agent and oxidant dose, which were added, were negligible when compared with the total volume of treated wastewater. The samples were drawn at regular intervals for conducting the analyses including, $\mathrm{COD}, \mathrm{BOD}_{5}$, TOC, and residual dye concentrations. Eq. 3 was used to calculate the degradation efficiency or efficiency (\%) of the AB80.

$$
\text { Efficiency }(\%)=\left[\frac{\left(C_{0}-C_{t}\right)}{C_{0}}\right] \times 100
$$

By using the open reflux method, the COD values were measured. This method, in brief, is described as follows: Under acidic conditions, the organic matter is oxidised using potassium 
dichromate. The $\mathrm{BOD}_{5}$ value was estimated by determining the oxygen consumption by titrating with sodium thiosulphate, post incubation for five days. The intensity of colour was measured at $400 \mathrm{~nm}$, as the maximum wavelength using a UV-Vis spectrophotometer (Hach DR5000). To determine the quantity of decomposed organic carbon, a measuring device (TOC model (Multi NC3100, made in Germany) was used.

\section{Results and Discussion}

\subsection{Effect of pH}

One of the very important parameters in pollutant degradation that alters the performance of the AOP process most of the time is the $\mathrm{pH}$ of the solution. The effects of $\mathrm{pH}$ at the values of $3,5,7,9$, and 11 for the UV/PS, $\mathrm{UV} / \mathrm{H}_{2} \mathrm{O}_{2}$, and $\mathrm{UV} / \mathrm{PS} / \mathrm{H}_{2} \mathrm{O}_{2}$ systems were considered in this study and the results are shown in Fig 1a. The experiments were performed at a contact time of $60 \mathrm{~min}$ at an initial concentration of $25 \mathrm{mg} / \mathrm{L}$ and radiation intensity of 36 watts and a concentration of oxidants of $15 \mathrm{mmol}$. For the UV/PS system, the best performance for dye degradation is achieved at $\mathrm{pH}$ of 7 . Although no significant difference is noted between the removal efficiency at $\mathrm{pH}$ of 5 and 7 , that is in acidic and alkaline $\mathrm{pH}$, the efficiency shows a reduction, which in corresponding reports acknowledges that the best $\mathrm{pH}$ while employing UV/PS to eliminate the pollutants was within the almost neutral range (Ahmed et al., 2012; Yang et al., 2016). At alkaline $\mathrm{pH}$, theSO ${ }_{4}^{-}$species reacts with the $\mathrm{OH}^{-}$to produce $\mathrm{OH}^{\circ}$ radicals, according to Equation 5. Despite the conversion of the $\mathrm{SO}_{4}^{--}$to $\mathrm{SO}_{4}^{-2}$ and the generation of the $\mathrm{OH}^{\circ}$ radicals with a redox potential of $2.8 \mathrm{~V}$, a slightly higher value than the redox potential of the $\mathrm{SO}_{4}^{\circ-}$, the presence of the $\mathrm{SO}_{4}^{-2}$ ions can inactivate the $\mathrm{OH}^{\circ}$ and $\mathrm{SO}_{4}^{\circ-}$ species (Zhang et al., 2016). Besides, the $\mathrm{CO}_{2}$ from the mineralisation of organic matter can result in the formation of bicarbonates and carbonates (as radical scavengers) under alkaline conditions. On the other 
hand, at an acidic $\mathrm{pH}$, additional $\mathrm{SO}_{4}^{\circ-}$ can be produced under acid catalysis, according to the equations 6 and 7 (Zhang et al., 2016; Yuan et al., 2011).

$\mathrm{SO}_{4}^{\circ-}+\mathrm{H}_{2} \mathrm{O} \rightarrow \mathrm{SO}_{4}^{-2}+\mathrm{OH}^{\circ}+\mathrm{H}^{+} \quad($ at all $\mathrm{pH})$

$\mathrm{SO}_{4}^{\circ-}+\mathrm{OH}^{-} \rightarrow \mathrm{SO}_{4}^{-2}+\mathrm{OH}^{\circ} \quad($ mostly in alkaline $\mathrm{pH})$

$\mathrm{S}_{2} \mathrm{O}_{8}^{-2}+\mathrm{H}^{+} \rightarrow \mathrm{HS}_{2} \mathrm{O}_{8}^{-}$

$\mathrm{HS}_{2} \mathrm{O}_{8}^{-} \rightarrow 2 \mathrm{SO}_{4}^{\circ-}+\mathrm{H}^{+}$

When excess PS radicals are generated, it can increase the concentration of the radicals which may react with each other, instead of reacting with the organic pollutants (Yang et al., 2016).

For the $\mathrm{UV} / \mathrm{H}_{2} \mathrm{O}_{2}$ process, the best removal efficiency was observed to occur at $\mathrm{pH}$ of 5 , showed a decline in performance as the $\mathrm{pH}$ increased. At alkaline $\mathrm{pH}$, the redox potential of the $\mathrm{OH}^{\circ}$ radical was reduced. Also, $\mathrm{H}_{2} \mathrm{O}_{2}$ may be decomposed into water and oxygen at high $\mathrm{pH}$ levels, as shown (Yao et al., 2013):

$2 \mathrm{H}_{2} \mathrm{O}_{2} \rightarrow 2 \mathrm{H}_{2} \mathrm{O}+\mathrm{O}_{2}$

Further, in a low acidic environment, the $\mathrm{H}_{2} \mathrm{O}_{2}$ molecules react with the excess $\mathrm{H}^{+}$ions to form oxonium ions $\left(\mathrm{H}_{3} \mathrm{O}_{2}^{+}\right)$which are stable and cannot form the $\mathrm{OH}^{\circ}$ radicals under ultraviolet radiation. At the same time, the excess $\mathrm{H}^{+}$ions may scavenge the generated $\mathrm{OH}^{\circ}$ radicals. For the $\mathrm{UV} / \mathrm{PS} / \mathrm{H}_{2} \mathrm{O}_{2}$, the best $\mathrm{pH}$ was identified as 5, the reasons for which have been stated above and also mentioned in various articles (Wu et al., 2015; Xie et al., 2015).

\subsection{Effect of oxidant concentration}

The effects of the $\mathrm{H}_{2} \mathrm{O}_{2}$ and PS concentrations on the rate of the removal of the AB80 dye were investigated and the results are listed in Figure $1 \mathrm{~b}$. The experiments were performed at a contact time of $60 \mathrm{~min}$ at an initial concentration of $25 \mathrm{mg} / \mathrm{L}$ and radiation intensity of $36 \mathrm{watts}$ and a $\mathrm{pH}$ of 7. As is evident, the rate of dye removal increased as the PS concentration surged up to 
$15 \mathrm{mmol}$, caused by the production of the $\mathrm{SO}_{4}^{\circ}$ radicals in response to the rise in the PS concentration. Also, with the increase in the concentration of $15 \mathrm{mmol}$, the removal rate declined, the reason being clarified as follows: the $\mathrm{SO}_{4}^{\circ}$ radical is converted to the PS radical according to equations 9 and 10 with lower reduction-oxidation potential than the $\mathrm{SO}_{4}^{\circ}$ radical (Yan et al., 2015). On the other hand, the $\mathrm{SO}_{4}^{\circ}$ radical acts as a scavenger radical and becomes a factor that facilitates the conversion of the $\mathrm{SO}_{4}^{\circ}$ radical to PS (Yan et al., 2011).

$\mathrm{S}_{2} \mathrm{O}_{8}^{-2}+\mathrm{SO}_{4}^{\circ} \rightarrow \mathrm{SO}_{4}^{-2}+\mathrm{S}_{2} \mathrm{O}_{8}^{\circ-}$

$\mathrm{SO}_{4}^{\circ}+\mathrm{SO}_{4}^{\circ} \rightarrow \mathrm{S}_{2} 0_{8}^{-2}$

Therefore, an increase in the concentration of $\mathrm{H}_{2} \mathrm{O}_{2}$ to $15 \mathrm{mmol}$ also improves the removal efficiency, caused by the production of the $\mathrm{OH}^{\circ}$ radicals; however, with further increase in the $\mathrm{H}_{2} \mathrm{O}_{2}$ levels, the removal efficiency decreases, due to the scavenging of the $\mathrm{OH}^{\circ}$ radicals available and the formation of hydroperoxyl $\left(\mathrm{HO}_{2}^{\circ}\right)$; these are the weaker radicals, less active than the $\mathrm{OH}^{\circ}$ radicals (Sun et al., 2016).

The use of two oxidants was simultaneously investigated, and the $12 \mathrm{mmol}$ concentration was selected as the optimal concentration of the oxidants in the combined process, although not much difference in the scavenging activity is observed between the 8 and $12 \mathrm{mmol}$ concentrations, and the high concentrations (Tan et al., 2014).

\subsection{Effect of radiation intensity}

One of the most important parameters in this study of the process of photolysis is the radiation, given at intensities of $8,5,24$, and $36 \mathrm{~W}$, in the combined process of $\mathrm{UV} / \mathrm{PS} / \mathrm{H}_{2} \mathrm{O}_{2}$; when the radiation intensity was increased from 8 to $36 \mathrm{~W}$, the removal efficiency was also seen to rise, so that in $60 \mathrm{~min}$, the removal rate was $74.6 \%$ at the radiation intensity of $8 \mathrm{~W}$. However, at the same time, at the radiation intensity of $36 \mathrm{~W}$, the removal rate was $98.2 \%$ (Fig 1c). This 
increase in the removal rate induced by the increase in the intensity of the irradiated radiation resulted in an increase in the number of excited electrons, which ultimately enhanced the generation of active $\mathrm{OH}^{\circ}$ or $\mathrm{SO}_{4}^{\circ-}$ (Yuan et al., 2014). The experiments were performed at a initial concentration of $100 \mathrm{mg} / \mathrm{L}$ and $\mathrm{pH}$ of 7 and a concentration of oxidants of $15 \mathrm{mmol}$.

\subsection{Effect of initial AB80 dye concentration and irradiation time}

The effect of the initial dye concentration at concentrations of $10,25,50$, and $100 \mathrm{mg} / \mathrm{L}$ on the combined process was performed using the optimal quantity of oxidants and $\mathrm{pH}$, and the results are shown in Figure 1d. The experiments were performed at a $\mathrm{pH}$ of 7 watts and a concentration of oxidants of $15 \mathrm{mmol}$. As depicted, at the $25 \mathrm{mg} / \mathrm{L}$ concentration, the highest removal efficiency (98.2\%) was obtained, which declined in response to the increase in concentration. The reason for this occurrence is explained as follows: Although the initial concentration of the dye is increased, the production rate of $\mathrm{OH}^{\circ}$ or $\mathrm{SO}_{4}^{-}$is remains constant during the process (Kwon et al., 2015). Further, the UV absorption by the dye molecules shows a surge in response to the increase in the dye concentration, thus preventing the activation of the oxidants (Wols et al., 2015).

Irradiation time and contact time are other crucial parameters that were examined and shown in Figure 1d, and as is obvious, when the irradiation time increases from 10 to $60 \mathrm{~min}$, the removal rate also rises significantly. In terms of irradiation time, the exposure of the oxidants of $\mathrm{H}_{2} \mathrm{O}_{2}$ and PS to ultraviolet light activates them. Therefore, as the radiation time increases, more electrons are produced, which thus generate more $\mathrm{OH}^{\circ}$ and $\mathrm{SO}_{4}^{\circ}$ radicals and provides great opportunity for the active $\mathrm{OH}^{\circ}$ and $\mathrm{SO}_{4}^{\circ}$ - radicals to degrade the $\mathrm{AB} 80$ dye (Rastogi et al., 2009). 


\subsection{Comparison of the dye removal by different processes}

239 After determining the optimum conditions in the earlier steps, the effect of each oxidant alone and the effect of their simultaneous use during the different processes involved in the removal

241 of the AB80 dye was studied, the results of which are shown in Figure 1e. Considering the 242 results of the prior steps, the study was performed in 10-60 min of contact time under the 243 optimum values of the parameters, including the $15 \mathrm{mmol}$ doses of PS and $\mathrm{H}_{2} \mathrm{O}_{2}, 36 \mathrm{~W}$ of radiation intensity, and $25 \mathrm{mg} / \mathrm{L}$ of dye concentration, at $\mathrm{pH}$ of 7 . As observed, the process efficiencies of the $\mathrm{H}_{2} \mathrm{O}_{2}, \mathrm{UV} / \mathrm{H}_{2} \mathrm{O}_{2}, \mathrm{UV}$, UV/PS, PS, and UV/PS/ $\mathrm{H}_{2} \mathrm{O}_{2}$ in dye removal are different, with very low efficiency of the $\mathrm{H}_{2} \mathrm{O}_{2}$, UV and PS processes. Moreover, from these results, the UV/PS/ $\mathrm{H}_{2} \mathrm{O}_{2}$ process reveals the highest removal efficiency, eliminating $98.2 \%$ of the AB80 dye in 60 min. This increase in efficiency for the combined process can be attributed to the UV-induced activation of $\mathrm{S}_{2} \mathrm{O}_{8}^{-2}$ or $\mathrm{H}_{2} \mathrm{O}_{2}$ because the UV light, according to equations 1 and 2, produces the $\mathrm{OH}^{\circ}$ or $\mathrm{SO}_{4}^{-}$radicals, considered the strongest oxidants (Wols et al., 2014;

251 Wols et al., 2015).
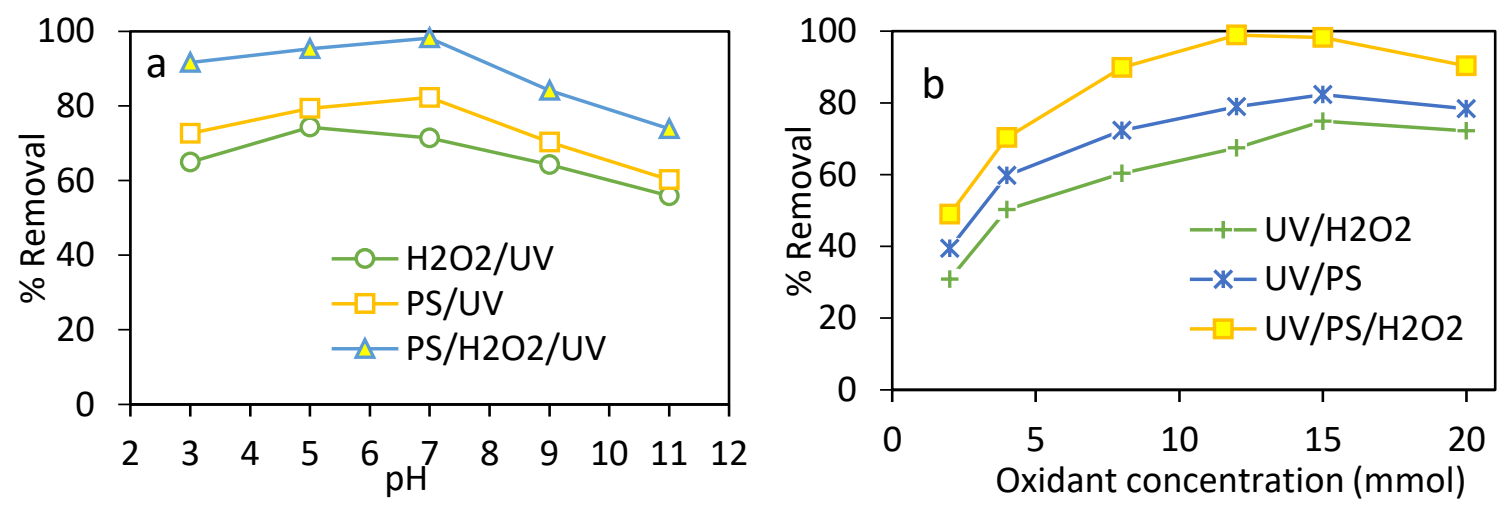

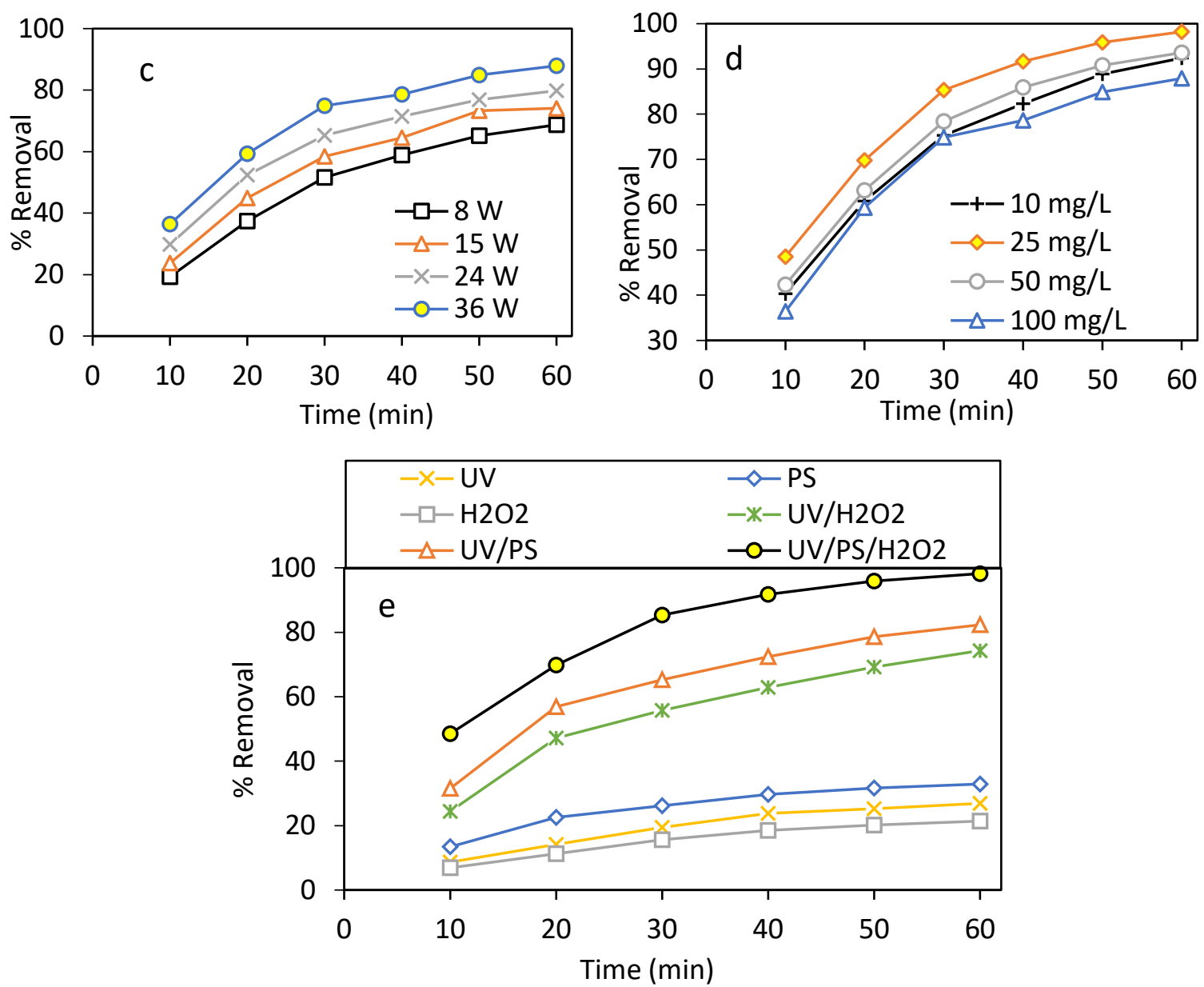

254

Figure 1. The effect of $\mathrm{pH}$ (a), concentrations of PS and $\mathrm{H}_{2} \mathrm{O}_{2}$ (b), UV light intensity (c), initial concentration of AB80 dye (d), and various processes (e) on the photochemical degradation efficiency of AB80 dye

\subsection{Mineralisation assessment}

The TOC analysis can offer a measure of the degree of mineralisation of the AB80 dye. The quantity mineralised occurred under the optimal conditions obtained from the previous steps, where the AB80 dye concentration at this stage of the study was considered to be $100 \mathrm{mg} / \mathrm{L}$, and the quantity mineralised was determined at different times. The initial TOC level for 100 $\mathrm{mg} / \mathrm{L}$ concentration was found to be $65.6 \mathrm{mg} / \mathrm{L}$.

The TOC results for a comparison of the three UV/PS/ $\mathrm{H}_{2} \mathrm{O}_{2}, \mathrm{UV} / \mathrm{H}_{2} \mathrm{O}_{2}$, and UV/PS systems are shown in Figure 2a. Note that the efficiency based on TOC for this case is defined as follows (Zhang et al., 2014): 
268

Where $\mathrm{TOC}_{0}$ and $\mathrm{TOC}_{\mathrm{t}}$ are the TOC concentrations measured at the beginning and after a specific time of the degradation process, respectively.

As observed from Figure 2a, the amount of mineralisation increases with the increase in degradation time, but when compared to the other two systems it was much higher for the combined system. In fact, around $92.1 \%$ of the TOC is removed by the combined system in 120 min, while only $50.95 \%$ is removed for the $\mathrm{UV} / \mathrm{H}_{2} \mathrm{O}_{2}$ system and about $59.1 \%$ for the UV/PS system.

\subsection{Improvement of biodegradability}

Due to the toxicity of industrial wastewater, biological processes alone do not have the efficiency, adequate to treat industrial wastewater. The AOPs processes, on the other hand, are expensive when used only to treat the organic compounds. As they had the capacity to improve the effluent quality, the AOPs can be used to treat toxic and strong wastewater prior to submitting them to biological treatment (Yu et al., 2004). In order to evaluate the biodegradability of the treated effluent, the $\mathrm{BOD}_{5} / \mathrm{COD}$ index is employed as a common index. The $\mathrm{BOD}_{5} / \mathrm{COD}$ ratio was initially 0.19 , which is indicative of the low biodegradability of coloured wastewater. It is significant that for biodegradability, this ratio should be greater than 0.4. Figure $2 \mathrm{~b}$ shows the $\mathrm{BOD}_{5} / \mathrm{COD}$ values after different processes within a photolytic time of 120 min. In the UV, PS, and $\mathrm{H}_{2} \mathrm{O}_{2}$ systems, the degree of biodegradability showed no significant change and increased from 0.19 to about only 0.23 , which can normally be attributed to the $\mathrm{COD}$ and $\mathrm{BOD}_{5}$ reduction in solution. Therefore, the wastewater continues to be nonbiodegradable. But for the combined UV/PS/ $\mathrm{H}_{2} \mathrm{O}_{2}$ system, this rate goes up to $52.4 \%$, and the wastewater becomes biodegradable; therefore, in this system, it can be stated that the nonbiodegradable materials have become simpler materials. 


\subsection{The role of radical species}

292 To evaluate the contribution of the $\mathrm{OH}^{\circ}$ or $\mathrm{SO}_{4}^{-}$radicals to the efficiency of the $\mathrm{UV} / \mathrm{PS} / \mathrm{H}_{2} \mathrm{O}_{2}$ process, two alcoholic radical scavengers, $\mathrm{EtOH}$ and $\mathrm{t}-\mathrm{BuOH}$, were added separately to the solutions. The EtOH can quench both $\mathrm{OH}^{\circ}$ or $\mathrm{SO}_{4}^{\circ}$ radicals. However, the t$\mathrm{BuOH}$ can destroy $\mathrm{OH}^{\circ}$ radicals principally and react weakly with the $\mathrm{SO}_{4}^{\circ}$ - radicals ( $\mathrm{Yu}$ et al., 2003; Khan et al., 2014). Accordingly, the difference in efficiency in the presence of these scavengers can be considered the contribution of the $\mathrm{SO}_{4}^{\circ}$ radicals. Therefore, in light of the efficiency of the system, coupled with these two scavengers, it is easy to understand the contribution of $\mathrm{OH}^{\circ}$ or $\mathrm{SO}_{4}^{\circ}$ radicals. As Figure 2c shows, the addition of EtOH in different quantities reduced the efficiency much more than the t-BuOH. For example, the addition of $1.4 \%(\mathrm{~V} / \mathrm{V}) \mathrm{EtOH}$ or $\mathrm{t}-\mathrm{BuOH}$ reduced the efficiency by $41 \%$ and $29 \%$, respectively, when compared to the normal state without the scavengers. These observations mean that both the radical species are involved in the degradation of the AB80 dye. It noteworthy that for the electron transfer reactions, the $\mathrm{SO}_{4}^{\circ-}$ radicals are found to be more selective, but the $\mathrm{OH}^{\circ}$ radicals can quickly participate in the reactions related to either the addition or abstraction of hydrogen 306 (Yu et al., 2004).

\subsection{Reaction kinetics}

In all the three systems, rapid rate of dye removal was seen, most likely due to the presence of the oxidants when the reaction commenced. To study the reaction rate, the pseudo-first-order kinetic model is most often used, (see formula given below) (Zhang et al., 2014):

$311 \ln \frac{\mathrm{C}_{\mathrm{o}}}{\mathrm{C}_{\mathrm{t}}}=\mathrm{k} \cdot \mathrm{t}$

312 Where the $\mathrm{C}_{0}$ and $\mathrm{C}_{\mathrm{t}}$ are the initial concentration and concentration post the photochemical reaction at time $\mathrm{t}$, and $\mathrm{k}$ is the constant rate of the pseudo-first-order reaction $(1 / \mathrm{min})$. The reaction rate constant is obtained by plotting the $\ln \mathrm{C}_{\mathrm{t}} / \mathrm{C}_{0}$ at time $\mathrm{t}$. The diagram desired is 
shown in Fig $2 \mathrm{~d}$. As is observed, the $\ln \mathrm{C}_{\mathrm{t}} / \mathrm{C}_{0}$ diagram at time $\mathrm{t}$ is linear for all three systems,

316 indicating a high regression coefficient and data adherence to the pseudo-first-order kinetics.

317 Also, the reaction rate constant for the UV/PS/ $\mathrm{H}_{2} \mathrm{O}_{2}, \mathrm{UV} / \mathrm{PS}$, and $\mathrm{UV} / \mathrm{H}_{2} \mathrm{O}_{2}$ combined systems 318 is $0.066,0.026$, and $0.02 \mathrm{~min}^{-1}$, respectively; thus, it can be said that the reaction rate for the $319 \mathrm{UV} / \mathrm{PS} / \mathrm{H}_{2} \mathrm{O}_{2}$ combined system is greater than that of the other two systems.
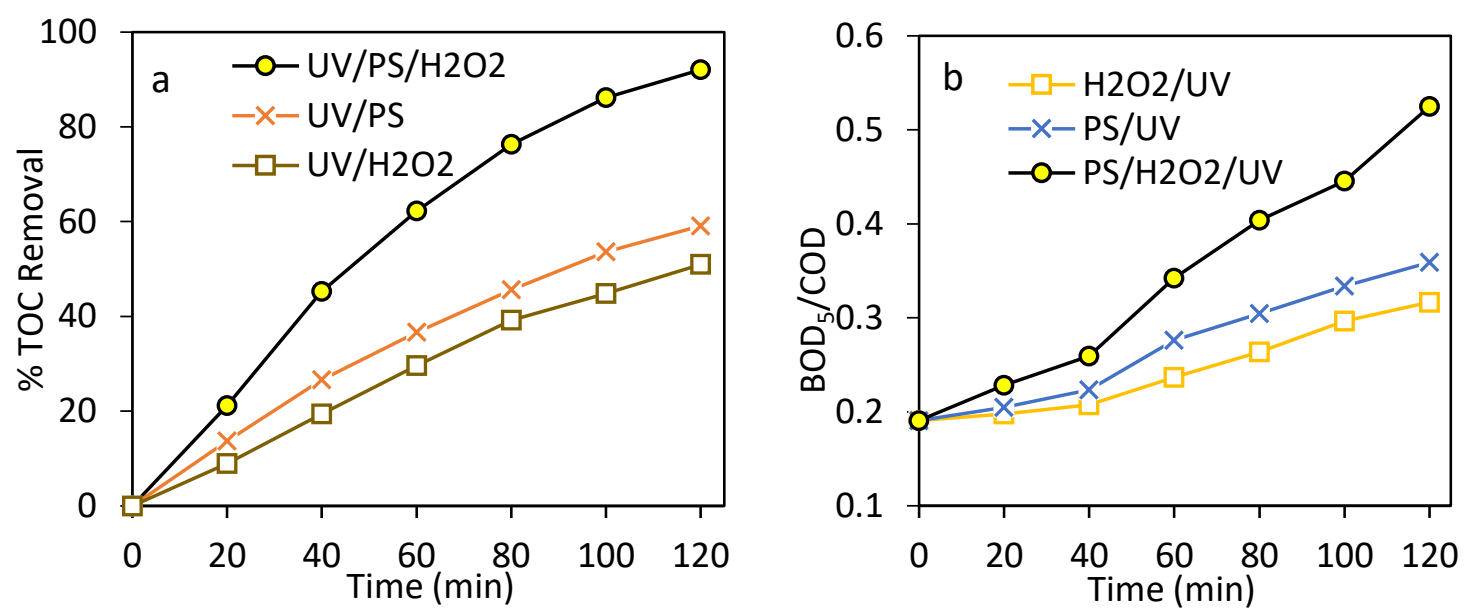

320
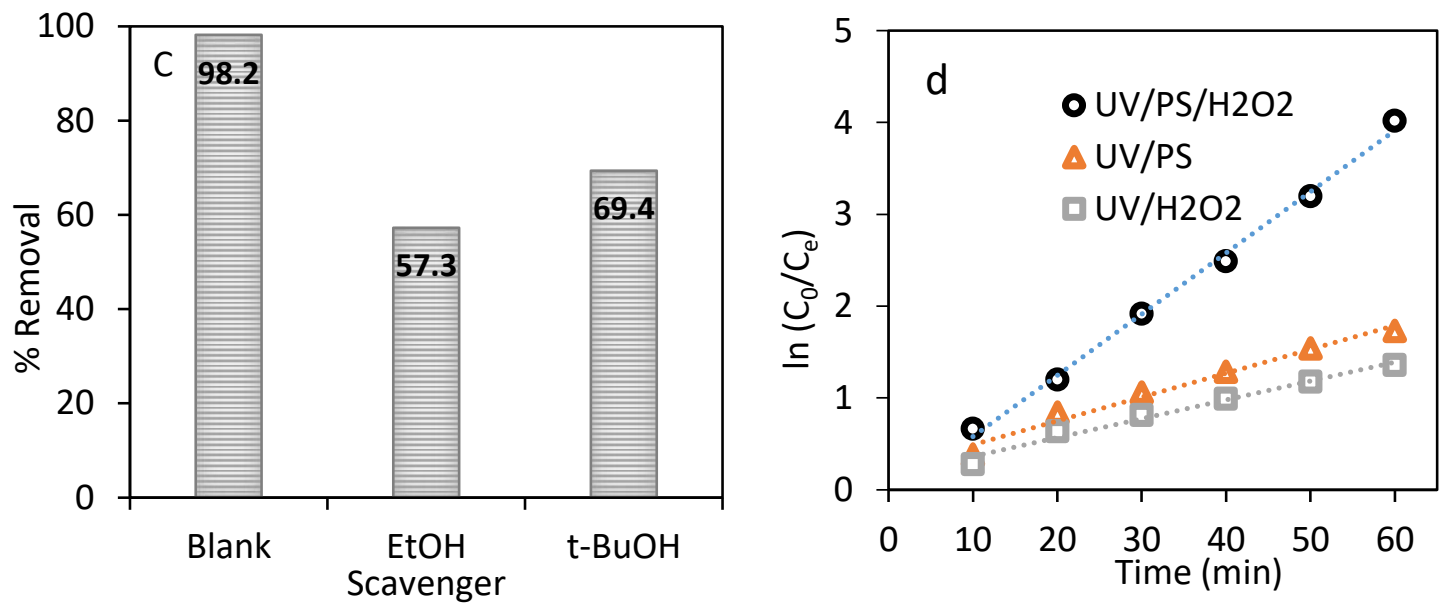

321

Figure 2. TOC removal efficiency (a), $\mathrm{BOD}_{5} / \mathrm{COD}$ rate for different processes (b), Effect of various scavengers (c), and pseudo-first order kinetics (d), for different removal methods

\subsection{Energy consumption}

One of the central parameters for the superiority of the technology used in wastewater treatment is the economic aspect, which most often is often critical. In this regard, electrical energy consumption (EEC) is the main share of the energy in the photochemical process. Here, the 
EEC can be calculated in accordance with the proposal of the International Union of Pure and Applied Chemistry, using the following equation (Khan et al., 2013).

$\mathrm{EEC}=\frac{\mathrm{P} \times \mathrm{t} \times 1000}{\mathrm{~V} \times 60 \times \log \left(\frac{\mathrm{C}_{0}}{\mathrm{C}_{\mathrm{e}}}\right)}$

Where $\mathrm{P}$ is the electrical power $(\mathrm{kW})$ of the photochemical system (generally targeting radiation energy), $\mathrm{V}$ is the volume of the solution in the reactor in litres, and $\mathrm{t}$ is the reaction time (min).

Therefore, the EEC required for the photochemical degradation of the AB80 dye solution employing the processes of $\mathrm{UV} / \mathrm{H}_{2} \mathrm{O}_{2}, \mathrm{UV} / \mathrm{PS}$, and $\mathrm{UV} / \mathrm{PS} / \mathrm{H}_{2} \mathrm{O}_{2}$ are $61,47.8$, and 20.8 $\mathrm{kWh} / \mathrm{m}^{3}$, respectively, and as observed, for the combined UV/PS/ $\mathrm{H}_{2} \mathrm{O}_{2}$ system, the energy consumed is less than that in the other two systems. In a study conducted to ascertain the removal of atrazine using the photochemical process by $\mathrm{UV} / \mathrm{H}_{2} \mathrm{O}_{2} / \mathrm{Fe}+{ }^{2}$, the energy consumed is equal to $76.2 \mathrm{kWh} / \mathrm{m}^{3}$, which is higher than the energy consumed in this study (Khan et al., 2013). The expenditure involved for the electricity consumed was calculated according to industrial consumption and based on Iran, it is equal to US dollar 0.064 per $1 \mathrm{kWh}$ for the combined system.

\subsection{Toxicity test}

The bioassay using Daphnia magna was used to test the solution toxicity. Daphnia was selected for this purpose due to its brief reproduction time, high sensitivity, simplicity of testing, and low laboratory costs, and most important, for its parthenogenesis, ranking high among the most crucial factors in the validity of the results drawn from a bio-experimental experiment (Sun et al., 2016). In this study, the Daphnia neonate was used instead of the adult Daphnia. When the adult Daphnia was used, it was possible to reproduce and increase the number of Daphnia in the samples under investigation, which would interfere with the test results and their uncertainty. To perform the toxicity test, a concentration of $25 \mathrm{mg} / \mathrm{L}$ of the $\mathrm{AB} 80$ dye solution 
was prepared. In the bioassay, the next step was to collect the three to four-day-old Daphnia neonates from the culture medium and dilute them up to three times in water, and wash for five minutes. Then, 10 Daphnia were dropped by pipette into each of the containers for testing. The number of Daphnia was counted after a contact time of 24 hours. No live Daphnia were found for the solution at $25 \mathrm{mg} / \mathrm{L}$ concentration after 24 hours, while for the control solution (without dye), all ten Daphnia were alive. After using the combined process of the UV/PS/ $\mathrm{H}_{2} \mathrm{O}_{2}$ and removal of the dye from the solution, the number of live Daphnia was 9 after 24 hours, showing that only one Daphnia was eliminated during this process. Therefore, it can be concluded that the effluent toxicity was reduced by $90 \%$. Also, the NOEC value (the concentration at which no effect was observed after 24 hours) was tested for AB80 dye; its value was observed to be $1.5 \mathrm{mg} / \mathrm{L}$. Further, the concentration at which $50 \%$ of the laboratory samples were destroyed, the so-called LC50 was established as $4.7 \mathrm{mg} / \mathrm{L}$ for the dye solution.

\section{Conclusion}

In this study, the performance of the UV/PS/ $\mathrm{H}_{2} \mathrm{O}_{2}, \mathrm{UV} / \mathrm{H}_{2} \mathrm{O}_{2}$, and UV/PS systems for the removal of the AB80 dye was evaluated, and these systems were compared in terms of energy consumption, mineralisation, toxicity, and reaction kinetics and biodegradability. The results of the study indicate that the parameters of $\mathrm{pH}$, oxidant concentration, system type, AB80 dye concentration, as well as reaction time show remarkable involvement in the production of the $\mathrm{OH}^{\circ}$ or $\mathrm{SO}_{4}^{\circ}$ radicals during the photochemical-oxidation processes based on the $\mathrm{H}_{2} \mathrm{O}_{2}$ and PS. In this photochemical system, an increase in the time and a decrease in the initial dye concentration and $\mathrm{pH}$, produced the desired efficiency in the removal of the AB80 dye. The combined UV/PS/ $\mathrm{H}_{2} \mathrm{O}_{2}$ process showed the capacity to remove $98.2 \%$ of the dye solution and minimise the toxicity of the effluent caused by Daphnia. As this system converts nonbiodegradable wastewater into biodegradable effluents, it is proposed that this system be used in the treatment of industrial wastewater prior to the biological systems. Reaction kinetics are 
pseudo first-order kinetics and the reaction rate is higher for the UV/PS/ $\mathrm{H}_{2} \mathrm{O}_{2}$ system than for any other systems. Also, in this study, mineralisation was accomplished using TOC, and from the results it is evident that mineralisation has been performed as well.

\section{Acknowledgements}

The authors wish to acknowledge the Health Research Deputy of Zahedan University of Medical Sciences, Iran, as well as the Chemical Laboratory of the School of Public Health, Zahedan University of Medical Sciences, Iran.

\section{Funding}

This work was supported by Zahedan University of Medical Sciences, Zahedan-Iran. (code:10296).

\section{Ethics approval and consent to participate}

Not applicable.

\section{Consent for publication}

Not applicable.

\section{Competing interests}

The authors declare no competing interests.

\section{-Authors Contributions}

All authors contributed to the study conception and design. Material preparation, data collection, and analysis were performed by Tariq J. Al-Musawi, Murat Yilmaz and Samaneh Mohebi. The first draft of the manuscript was written by Amir Hossein Mahvi and Davoud Balarak; all authors commented on previous versions of the manuscript. All authors read and approved the final manuscript.

Corresponding author

Correspondence to Davoud Balarak

\section{Availability of data and materials}

The datasets used and analyzed during the current study are available from the corresponding author on reasonable request.

\section{References}

Adeniyi, A.G., Ighalo, J.O., 2019. Biosorption of pollutants by plant leaves: an empirical review. J Environ Chem Eng. 7(3):103100. https ://doi.org/10.1016/j.jece.2019.10310. 
Adeogun, A.I., Balakrishnan, R.B., 2017. Kinetics, isothermal and thermodynamics studies of electrocoagulation removal of basic dye rhodamine B from aqueous solution using steel electrodes. Appl Water Sci. 7; 1711. https ://doi.org/10.1007/s1320 1-015-0337-4.

Ahmed, M., Barbati, S., Doumenq, P., Chiron, S., 2012. Sulfate radical anionoxidation of diclofenac and sulfamethoxazole for water decontamination. Chem. Eng. J. 197, 440447.

Ali, I., Alharbi, O.M., Al-Othman, Z.A., Badjah, A.Y., 2018. Kinetics, thermodynamics, and modeling of amido black dye photodegradation in water using $\mathrm{Co} / \mathrm{TiO}_{2}$ nanoparticles. Photochem Photobiol. 94:935-941. https ://doi.org/10.1111/php.12937.

Al-Musawi, T.J., Mengelizadeh, N., Al-Rawi, O., 2021. Capacity and Modeling of Acid Blue 113 Dye Adsorption onto Chitosan Magnetized by $\mathrm{Fe}_{2} \mathrm{O}_{3}$ Nanoparticles. J. Polymer. Environ. https://doi.org/10.1007/s10924-021-02200-8.

Al-Musawi, T.J., Rajiv, P., Mengelizadeh, N., Mohammed, I.A., 2021. Development of sonophotocatalytic process for degradation of acid orange 7 dye by using titanium dioxide nanoparticles/GO nanocomposite as a catalyst. J. Environ. Manage. 292, 112777.

Azarpira, H., 2016. Biosorption of acid orang 7 using dried cyperus rotundus: Isotherm studies and error functions. Int J ChemTech Res. 9(9), 543-549

Baeza, C., Knappe, D.R.U., 2011. Transformation kinetics of biochemically active compounds in low-pressure UV Photolysis and $\mathrm{UV} / \mathrm{H}_{2} \mathrm{O}_{2}$ advanced oxidation processes. Water Res. 45 (15), 4531-4543.

Balarak, D., Mostafapour, F.K., 2018. Adsorption of acid red 66 dye from aqueous solution by heat-treated rice husk. Res J Chem Environ. 22(12):80-84.

Balarak, D., Mahdavi, Y., Bazrafshan, E., Mahvi, A., 2016. Kinetic, isotherms and thermodynamic modeling for adsorption of acid blue 92 from aqueous solution by modified Azolla filicoloides. Fresen Environ Bull. 25(5):1321-1330.

Balarak, D., Zafariyan, M., Igwegbe, C.A., Onyechi, K.K., Ighalo, J.O., 2021. Adsorption of Acid Blue 92 Dye from Aqueous Solutions by Single-Walled Carbon Nanotubes: Isothermal, Kinetic, and Thermodynamic Studies. Environ Processes. 8(2), 869-888.

Balarak, D., Ganji, F., Choi, S.S., Lee, S.M., Shim, M.J., 2019. Effects of operational parameters on the removal of acid blue 25 dye from aqueous solutions by electrocoagulation. Appl. Chem. Eng. 30(6), 742-748.

Bulut, Y., Gozubenli, N., Aydin, H., 2007. Equilibrium and kinetics studies for adsorption of direct blue 71 from aqueous solution by wheat shells. J Hazard Mater. 144:300-307. https ://doi.org/10.1016/j.jhazmat.2006.10.027. 
Canonica, S., Meunier, L., Gunten, U., 2008. Phototransformation of selected pharmaceuticals during UV treatment of drinking water. Water Res. 42 (1-2),121-128.

Dotto, G., Pinto, L., 2011. Adsorption of food dyes acid blue 9 and food yellow 3 onto chitosan: Stirring rate effect in kinetics and mechanism. J Hazard Mater. 187(1-3):164-170. https ://doi.org/10.1016/j.jhazmat.2011.01.016.

Goshadrou, A., Moheb, A., 2011. Continuous fixed bed adsorption of CI Acid Blue 92 by exfoliated graphite: An experimental and modeling study. Desalination. 269(1-3):170176. https ://doi.org/10.1016/j.desal .2010.10.058.

Gupta, V.K., Kumar, R., Nayak, A., Saleh, T.A., Barakat, M., 2013. Adsorptive removal of dyes from aqueous solution onto carbon nanotubes: a review. Adv Colloid Interf Sci. 193: $24-34$

Igwegbe, C.A., Onyechi, P.C., Onukwuli, O.D., Nwokedi, I.C., Adsorptive treatment of textile wastewater using activated carbon produced from Mucunapruriens seed shells. World J Eng Technol. 2016; 4(1):21-37. https ://doi.org/10.4236/wjet.2016.41003.

Iram, M., Guo, C., Guan, Y., Ishfaq, A., Liu, H., 2010. Adsorption and magnetic removal of neutral red dye from aqueous solution using $\mathrm{Fe}_{3} \mathrm{O}_{4}$ hollow nanospheres. J. Hazard. Mater 181(1-3):1039-1050. https ://doi.org/10.1016/j.jhazm at.2010.05.119.

Jauris, I.M., Fagan, S.B., Adebayo, M.A., Machado, F.M., 2016. Adsorption of acridine orange and methylene blue synthetic dyes and anthracene on single wall carbon nanotubes: a first principle approach. Comput Theoretic Chem. 1076:42-50.

Keen, O.S., Linden, K.G., 2013. Degradation of antibiotic activity during $\mathrm{UV} / \mathrm{H}_{2} \mathrm{O}_{2}$ advanced oxidation and photolysis in wastewater effluent. Environ. Sci. Technol. 47 (22), 1302013030.

Khan, J.A., He, X., Shah, N.S., Khan, H.M., Hapeshi, E., Dionysiou, DD., 2014. Kinetic and mechanism investigation on the photochemical degradation of atrazine with activated $\mathrm{H}_{2} \mathrm{O}_{2}, \mathrm{~S}_{2} \mathrm{O}_{2}^{-8}$. Chem. Eng. J. 252, 393-403.

Khan, J.A., He, X., Khan, H.M., Shah, N.S., Dionysiou, D.D., 2013. Oxidative degradation of atrazine in aqueous solution by $\mathrm{UV} / \mathrm{H}_{2} \mathrm{O}_{2} / \mathrm{Fe}+{ }^{2}, \mathrm{UV} / \mathrm{S}_{2} \mathrm{O}_{2}{ }^{-8} / \mathrm{Fe}^{+2}$ and $\mathrm{UV} / \mathrm{HSO}^{-5} / \mathrm{Fe}^{+2}$ processes: a comparative study. Chem. Eng. J. 218, 376-383.

Kwon, M., Kim, S., Yoon, Y., Jung, Y., Hwang, T.M., Lee, J., Kang, J.W., 2015. Comparative evaluation of ibuprofen removal by $\mathrm{UV} / \mathrm{H}_{2} \mathrm{O}_{2}$ and $\mathrm{UV} / \mathrm{S}_{2} \mathrm{O}_{2}$ processes for wastewater treatment. Chem. Eng. J. 269, 379-390. 
Machado, F.M., Carmalin, S.A., Lima, E.C., Dias, S.L., Prola, L.D., Saucier, C., Jauris, I.M., Zanella, I., Fagan, S.B., 2016. Adsorption of Alizarin Red S dye by carbon nanotubes: An experimental and theoretical investigation. J Physic Chem. 120: 18296-18306.

Menkiti, M., Aniagor, C., Agu, C., Ugonabo, V., 2018. Effective adsorption of crystal violet dye from an aqueous solution using lignin-rich isolate from elephant grass. Water Conserv Sci Eng. 3(1):33-46. https ://doi.org/10.1007/s4110 1-017-0040-4.

Rastogi, A., Al-Abed, S.R., Dionysiou, D.D., 2009. Sulfate radical-based ferrouseperoxymonosulfate oxidative system for PCBs degradation in aqueous and sediment systems. Appl. Catal. B Environ. 85(3), 171-179.

Sillanpää, M., Mahvi, A.H., 2021. Adsorption of Acid orange 7 dyes from aqueous solution using Polypyrrole/nanosilica composite: Experimental and modelling. Int. J. Environ. Anal. Chem. https://doi.org/10.1080/03067319.2020.1855338.

Sun, P., Tyree, C., Huang, C.H., 2016. Inactivation of E. coli, Bacteriophage MS2 and Bacillus spores under $\mathrm{UV} / \mathrm{H}_{2} \mathrm{O}_{2}$ and $\mathrm{UV} /$ peroxydisulfate advanced disinfection conditions. Environ. Sci. Technol. 50(8), 4448e4458.

Tan, C., Gao, N., Zhou, S., Xiao, Y., Zhuang, Z., Kinetic study of acetaminophen degradation by UV-based advanced oxidation processes. Chem. Eng. J. 2014; 253,229-236.

Wols, B.A., Harmsen, D.J.H., Beerendonk, E.F., Hofman-Caris, C.H.M., 2014. Predicting pharmaceutical degradation by UV (LP)/ $\mathrm{H}_{2} \mathrm{O}_{2}$ processes: a kinetic model. Chem. Eng. J. 255 (6), 334-343.

Wols, B.A., Harmsen, D.J.H., Beerendonk, E.F., Hofman-Caris, C.H.M., 2015. Predicting pharmaceutical degradation by UV (MP)/ $\mathrm{H}_{2} \mathrm{O}_{2}$ processes: a kinetic model. Chem. Eng. J. 263, 336-345.

Wols, B.A., Harmsen, D.J.H., Wanders-Dijk, J., Beerendonk, E.F., Hofman-Caris, C.H.M., 2015. Degradation of pharmaceuticals in UV (LP)/ $\mathrm{H}_{2} \mathrm{O}_{2}$ reactors simulated by means of kinetic modelling and computational fluid dynamics (CFD). Water Res. 75, 11-24.

Wu, J.T., Wu, C.H., Liu, C.Y., Huang, W.J., 2015. Photodegradation of sulfonamideanti microbial compounds in various UV/oxidant systems. Water Sci. Technol. 71 (3),412417.

Xie, P., Ma, J., Liu, W., Zou, J., Yue, S., Li, X., Wiesner, M.R., Fang, J., 2015. Removal of 2MIB and geosmin using UV/persulfate: contributions of hydroxyl and sulfateradicals. Water Res. 69, 223-233. 
Yang, Y., Pignatello, J.J., Ma, J., Mitch, W.A., 2016. Effect of matrix components on UV/ $\mathrm{H}_{2} \mathrm{O}_{2}$ and $\mathrm{UV} / \mathrm{S}_{2} \mathrm{O} 88_{2}$ advanced oxidation processes for trace organic degradation in reverse osmosis brines from municipal wastewater reuse facilities. Water Res. 89, 192-200.

Yan, F., Ji, Y., Kong, D., Lu, J., Zhou, Q., 2015. Kinetic and mechanistic investigations of the degradation of sulfamethazine in heat-activated persulfate oxidation process. J. Hazard. Mater. 300, 39-47.

Yan, J., Lei, M., Zhu, L., Anjum, M.N., Zou, J., Tang, H., 2011. Degradation of sulfamonomethoxine with $\mathrm{Fe}_{3} \mathrm{O}_{4}$ magnetic nanoparticles as heterogeneous activator of persulfate. J. Hazard. Mater. 186 (2-3), 1398-1404.

Yao, H., Sun, P., Minakata, D., Crittenden, J.C., Huang, C.H., 2013. Kinetics and modelling of degradation of ionophore antibiotics by $\mathrm{UV}$ and $\mathrm{UV} / \mathrm{H}_{2} \mathrm{O}_{2}$. Environ. Sci. Technol. 47 (9), 4581-4589.

Yuan, F., Hu, C., Hu, X., Wei, D., Chen, Y., Qu, J., 2011. Photodegradation and toxicity changes of antibiotics in UV and $\mathrm{UV} / \mathrm{H}_{2} \mathrm{O}_{2}$ process. J. Hazard. Mater. 185 (2-3), 12561263.

Yuan, R., Wang, Z., Hu, Y., Wang, B., Gao, S., 2014. Probing the radical chemistry in UV/persulfate-based saline wastewater treatment: kinetics modeling and by-products identification. Chemosphere. 109, 106-112.

Yu, X.Y., Bao, A.C., Barker, J.R., 2004. Free radical reactions involving $\mathrm{Cl}_{2}, \mathrm{Cl}_{2} \mathrm{O}$, and $\mathrm{SO}_{4}$ in the $248 \mathrm{~nm}$ photolysis of aqueous solutions containing $\mathrm{S}_{2} \mathrm{O}_{8}$ and $\mathrm{Cl}_{2}$. J. Phys. Chem. A. 108 (2), 295-308.

Yu, X.Y., Barker, J.R., 2003. Hydrogen peroxide photolysis in acidic aqueous solutions containing chloride ions. II. Quantum yield of $\mathrm{H}_{2} \mathrm{O}_{2}$ radicals. J. Phys. Chem. A. 107 (9), 1325-1332.

Zhang, R., Sun, P., Boyer, T.H., Zhao, L., Huang, C.H., 2016. Degradation of pharmaceuticals and metabolite in synthetic human urine by UV, UV/ $\mathrm{H}_{2} \mathrm{O}_{2}$, and UV/PDS. Environ. Sci. Technol. 49 (5), 3056-3066.

Zhang, R., Yang, Y., Huang, C.H., Li, N., Liu, H., Zhao, L., Sun, P., 2016. UV/H $\mathrm{H}_{2} \mathrm{O}_{2}$ and UV/PDS treatment of trimethoprim and sulfamethoxazole in synthetic humanurine: transformation products and toxicity. Environ. Sci. Technol. 50 (5), 2573-2583.

Zhang, T., Chen, Y., Wang, Y., Roux, J., Yang, Y., Croue, J.P., 2014. Efficient peroxydisulfate activation process not relying on sulphate radical generation for water pollutant degradation. Environ. Sci. Technol. 48 (10), 5868-5875. 


\section{Supplementary Files}

This is a list of supplementary files associated with this preprint. Click to download.

- GA.docx 